\title{
UNA CONSULTA A LOS LECTORES Y COLABORADORES
}

En el editorial del número anterior intentamos justificar la conveniencia de profundizar en el carácter internacional que Enseñanza de las Ciencias ha adquirido, proponiendo la publicación de algunos trabajos en su lengua original, acompañados de un amplio resumen en castellano. La importancia de dicha medida exigiría un amplio respaldo por lo que rogábamos se respondiera a un pequeño cuestionario al respecto. Las respuestas recibidas hasta ahora son insuficientes para adoptar una decisión, por lo que insistimos en nuestro ruego, reproduciendo de nuevo el cuestionario. Al mismo tiempo hemos incluido un artículo en portugués y una reseña de tesis doctoral en francés como ejemplos concretos cuya lectura puede facilitar la toma de decisión individual. El plazo de recepción de este cuestionario queda así ampliado al 30 de julio de 1990.

Nombre y apellidos

Dirección

Señale con una cruz la opción elegida:

1) Estoy de acuerdo con que Enseñanza de las Ciencias profundice en su carácter internacional publicando algunos trabajos en su lengua original, cuando ésta sea una lengua latina oel inglés, acompañados de un amplio resumen en castellano.

2) Preferiría que se continuara traduciendo todos los trabajos como se hace actualmente.

Rogamos igualmente cualquier otra sugerencia, crítica o comentario, que pueda contribuir a mejorar Enseñanza de las Ciencias. Agradecemos anticipadamente su colaboración. 